\title{
EL «EXPERIMENTO AMERICANO» \\ Y LOS ORÍGENES DEL CONCEPTO MODERNO \\ DE REVOLUCIÓN
}

\section{The "American experiment" and the origins of the modern concept of revolution}

\author{
MARCOS REGUERA \\ Universidad del País Vasco (UPV/EHU) \\ marcosreguera@gmail.com
}

Cómo citar/Citation

Reguera, M. (2018).

El «experimento americano» y los orígenes del concepto moderno de revolución. Revista de Estudios Políticos, 182, 71-98. doi: https://doi.org/10.18042/cepc/rep.182.03

\section{Resumen}

En este texto se explora la transformación que experimentó el concepto de revolución durante la guerra de la Independencia americana. Este evento coincide con un momento fundamental que el historiador Reinhart Koselleck denominó la Sattelzeit, un período histórico en que el vocabulario político que había dominado el lenguaje con pocos cambios pasa a sufrir grandes transformaciones repentinas. El principal objetivo del texto será mostrar cómo el uso tradicional del concepto de revolución reveló límites semánticos durante la Revolución americana, pues si bien había sido útil para explicar el levantamiento contra la metrópolis, resultó insuficiente para expresar la necesidad de llevar a cabo transformaciones sociales y políticas. Por lo que los Padres Fundadores se sirvieron del término experimento para completar el universo referencial que el concepto de revolución en aquel momento no llegaba a abarcar.

\section{Palabras clave}

Revolución; experimento; Revolución americana; Revolución francesa; Sattelzeit; historia conceptual; Padres Fundadores. 


\begin{abstract}
This article explores the conceptual change of revolution concept during the American Revolution. This event happened in a key historical moment that historian Reinhart Koselleck has called Sattelzeit, a historical period in which an unchanged political language suffered great and unexpected transformations. The main goal of my article will be to demonstrate how the old meaning of the concept revolution showed semantic limits during the American Revolution. While the old meaning of the concept was a useful rhetoric tool when the independence was seek in the north American colonies, it showed limitations when the revolutionary generation needed a notion to express their will to perform social and political changes. For that reason the Founding Fathers used the concept of experiment in order to get the political idea that the old concept of revolution can't express.
\end{abstract}

\title{
Keywords
}

Revolution; experiment; American Revolution; French Revolution; Sattelzeit; conceptual history; Founding Fathers. 


\section{SUMARIO}

I. EL TRÁNSITO DE LA VOZ TRADICIONAL AL CONCEPTO MODERNO DE REVOLUCIÓN. II. EXPLOSIÓN DE UN TÉRMINO PLURAL DURANTE LA GUERRA DE INDEPENDENCIA (1763-1786). III. DEBATES SOBRE LA CONSTITUCIÓN FEDERAL Y POPULARIZACIÓN DEL CONCEPTO DE EXPERIMENTO (1787-1789). IV. TERCERA FASE DEL CONCEPTO REVOLUTION EN LA REVOLUCIÓN AMERICANA: RADICALIZACIÓN DEL CONCEPTO POR LA REVOLUCIÓN FRANCESA (1789-1824). V. CONCLUSIONES. BIBLIOGRAFIA.

\section{EL TRÁNSITO DE LA VOZ TRADICIONAL AL CONCEPTO MODERNO DE REVOLUCIÓN}

Para dar cuenta de la transformación del concepto de revolución es necesario revisar primero las características que presentaba la noción tradicional del concepto, con el fin de comprender mejor las limitaciones con la que se encontraron los Padres Fundadores estadounidenses en su uso. Esta va a ser la tarea de este primer apartado, que si bien no va aportar grandes novedades al estado de la cuestión, considero que es importante presentar sus principales características y desarrollos para así comprender los límites referenciales del concepto tradicional en el momento en que estallan las revoluciones del mundo atlántico ${ }^{1}$.

Según el Merriam-Webster, el principal diccionario de lengua inglesa en Estados Unidos, revolution y revolt se transfirieron al inglés en el siglo $\mathrm{XIV}^{2}$, producto del contacto continuado con Francia por la guerra de los Cien Años. En dicha disputa se enfrentaban la casa Plantagenet contra los Valois por el trono de Francia, como resultado de la muerte del último rey Capeto, Carlos

1 Sobre las formulaciones antiguas de la noción de revolución existe una extensa literatura, de la que sobresalen los apartados dos y tres de la voz «Revolution, Rebellion, Aufruhr, Bürgerkriegdel» del diccionario de historia conceptual (Geschichtliche Grundbegriffe), los apartados escritos por Christian Meier "Revolution” in der Antike» y «Mittelater» de Jörg Fisch y Neihard Bulst.

2 Revolution. (n.d.). Disponible en: https://www.merriam-webster.com/dictionary/ revolution. 
IV, tío de Eduardo III de Inglaterra. La guerra de los Cien Años va a provocar, entre otras muchas situaciones, que la casa Plantagenet se esfuerce por conservar sus vínculos con Francia, manteniendo una política de casamientos regios con casas nobiliarias francesas y permitiendo la permeación de la cultura y lengua francesa en su corte y en los estratos nobiliarios ingleses.

Con ello se va a intensificar el proceso de desajonización y romanización de la lengua inglesa que ya había comenzado en tiempos de Guillermo el Conquistador con la suplantación de la nobleza sajona por la normanda. Multitud de vocabulario de origen latino va a pasar al inglés medio desde el francés medio en un proceso de solidificación durante toda la Edad Media que no va a cesar debido a la continua relación/conflicto entre los dos reinos por la disputa al trono de Francia.

En el siglo XIV, de todo ese flujo de vocabulario tomado del francés aparece, entre otros, en el inglés el término revolucioun como una adaptación al inglés medio del término coetáneo del francés medio révolution, que a su vez es copia casi exacta del latín tardío en su formulación revolutio, que evolucionó del latín clásico original en su formulación revolvere, siendo esta última también la raíz del concepto inglés revolt, que siguió un camino análogo al de revolution por idénticas razones ${ }^{3}$ (Williams, 2000: 281-282) ${ }^{4}$.

En esta raíz latina de revolución que el inglés toma del francés medieval se encuentra la clave del concepto tradicional de revolución, por lo que a continuación voy a realizar un repaso del origen del concepto tradicional desde la Roma antigua a su consolidación a finales del siglo xvir.

En la época tardía de la antigua Roma, el presente del infinitivo del verbo latino volvo (al que previamente se le había añadió el prefijo re-, que indica movimiento hacia atrás, generando la fórmula revolvere en algún momento del siglo Iv o del v d. C.) generó el sustantivo: revolutio, para cristalizar el significado de la fórmula verbal original que significaba «retroceder, desenrollar, girar y regresar ${ }^{6} »$. Este término tenía usos más allá de la política y en principio ninguno de ellos tenía que ver con el conflicto ni con la transformación social, sino que se trataba de una forma verbal que indicaba movimiento circular y

3 Revolution (n.d.). Disponible en: https://www.merriam-webster.com/dictionary/ revolution y Revolt. (n.d.). Disponible en: https://www.merriam-webster.com/ dictionary/revolt.

4 Agradezco a Miguel León que me proporcionase esta referencia, que me ha servido para confirmar la hipótesis del diccionario de Merriam-Webster.

5 Volvo (n.d.). Disponible en: http://www.perseus.tufts.edu/hopper/text?doc=Perseus: text:1999.04.0059:entry=volvo.

6 Revolvo (n.d.). Disponible en: http://www.perseus.tufts.edu/hopper/text?doc=Perseus: text:1999.04.0059:entry=revolvo. 
de retorno, y cuyas aplicaciones lingüísticas se empleaban en una infinidad de ámbitos. Por otra parte, en la antigua Roma existían múltiples términos para referirse al conflicto social ${ }^{7}$ al margen del tardío sustantivo de revolutio, tales como tumultus, turba, seditio, conjuratio, rebellio, discordia, bellum civile, motus y vicissitudo, pero ninguno de ellos aludía al cambio político y social, sino solo al conflicto dentro de la comunidad política (Koselleck, 2009: 163).

Para encontrar un término en la Roma clásica que determine tanto el conflicto político como la transformación social tenemos que acudir a la genealogía establecida por Hannah Arendt en su libro On Revolution (2009). En él la filósofa señala a la mutatio rerum como principal referencia para el conflicto social en la antigua Roma, estando esta emparentada con la fórmula propuesta por Polibio, la politeion anakuklosis (Politeíwn ỏnakúklwsis), fórmula que introdujo la idea griega de stasis (Stósis) (Arendt, 2009: 25). Esto es un paso importante en la prefiguración del concepto moderno de revolución, pues Aristóteles en su libro V de la Política, en el que enfrenta el problema de las rebeliones, el conflicto y el cambio social en la polis, señaló un punto que será muy importante para toda teoría revolucionaria moderna, y es que el problema de la stasis es producto de la desigualdad de la riqueza y de cómo esto a su vez influye en la capacidad de los muchos pobres y los pocos ricos para determinar la forma de gobierno de la comunidad política (Aristóteles, 2010: 200).

El modelo del conflicto social en Aristóteles es una teoría de corte inmanente sobre la corrupción de las formas virtuosas de gobierno y la guerra interna que estas traen consigo: junto con la corrupción de la monarquía que deviene en tiranía, encontramos el dúo bifurcado de contraconceptos virtuosos de aristocracia-politeia y sus formas corruptas oligarquía-democracia. El cambio es doble, primero de forma virtuosa a forma corrupta y luego, mediante una guerra civil, se restaura una nueva forma virtuosa. Tanto cuando los pocos mejores devienen en los pocos ricos que gobiernan la polis en beneficio propio (paso de la aristocracia a la oligarquía) como cuando el régimen mixto denominado politeia (Politeía) es dominado por los demagogos que incitan a los muchos pobres a gobernar al margen de la minoría rica (lo que deviene en la forma corrupta de la democracia), al final hay una rebelión en la polis que restaura una forma virtuosa de gobierno, pero de antemano el hecho de que exista una forma concreta de gobierno corrupto no lleva necesariamente a ninguna forma virtuosa concreta en el momento de la restauración, y por supuesto no aparece ninguna forma nueva de gobierno fuera de la doble triada propuesta por Aristóteles (ibid.: 198-208).

7 Y casi todos ellos han transitado a las lenguas romances con pocos cambios en su significado. 
Desde este esquema que podríamos denominar "protoeconómico» y "protosociológico», que prefigura bajo otras claves algunos elementos de la teoría de la revolución que desarrollará el marxismo en la modernidad, se da un tránsito a un esquema distinto, que es el de Polibio, que combina la idea inmanente de sucesión de formas de gobierno virtuosas y corruptas con una noción de movimiento trascendente y circular de un patrón recurrente y necesario en la sucesión de las formas de gobierno y como restauración del ciclo político.

Polibio, autor griego radicado en la antigua Roma, traslada esta idea de su civilización madre a la experiencia histórica de su civilización adoptiva. En el capítulo II del libro VI de sus Historias, Polibio diferenciaba entre constituciones simples, por un lado, y mixta, por otro. A las constituciones simples, que son seis (tres virtuosas y tres corruptas), les vincula en el capítulo IV del libro VI la idea de la politeion anakuklosis, o anaciclosis, tal y como la hemos adaptado en castellano, mientras que la constitución mixta, vinculada a la experiencia de la república romana, es superior a las simples porque vence la dinámica de la anaciclosis al incorporar todas las formas de gobierno virtuosas en una sola (que es también la idea de la politeia aristotélica).

Para Polibio la forma originaria y natural del gobierno de la polis es la monarquía, que degenera en tiranía por los abusos del poder real. Esto conduce a una aristocracia donde gobiernan los pocos ricos, pero pronto el pueblo se irrita también por los abusos de esta élite movida por sus deseos de riqueza, lo que conlleva el descuido de las necesidades generales, y los pobres en rebeldía instauran una democracia, que mientras es regida por aquellos que se rebelaron se muestra justa; pero que con el tiempo las nuevas generaciones olvidan las luchas de sus padres y menosprecian las leyes, convirtiendo la democracia en oclocracia, o gobierno del populacho. Finalmente, al caos devenido de la oclocracia le sucede una nueva monarquía que restaura el gobierno de las leyes y reinicia el ciclo de virtud y decadencia que se sucederá a menos que se instaure un régimen mixto como el romano, que incluya a todas las partes y evite esta dinámica (Polibio, 1996).

El término que aparece en griego en el libro de Polibio para describir la anaciclosis es metabolai, como el que utiliza Platón, principal influencia en este punto para Polibio, y al igual que en Aristóteles en Polibio no hay lugar para la innovación en las formas de gobierno. En latín metabolai bien puede asimilarse a revolvere, dado que la raíz volvo se asimila a la palabra griega 'eluw, que comparte un universo referencial con metabolaí. Esta es la única vía que

8 Volvo (n.d.). Disponible en: http://www.perseus.tufts.edu/hopper/text?doc=Perseus: text:1999.04.0059:entry=volvo. 
encuentro para que la forma sustantivada de revolvere (es decir, revolutio) acabe asimilándose a la anaciclosis polibiana, ya que ambas coinciden en un punto fundamental. No siendo el sustantivo revolutio un concepto originario del mundo político, acaba en esa esfera, y para expresar lo mismo que la anaciclosis de Polibio. Revolutio es una vuelta que regresa al punto de partida, que traducido al imaginario político clásico romano plantea lo mismo que la mutatio rerum de la anaciclosis, una mutación de la forma política que se da como un ciclo, que es el significado último del término romano revolutio. Sin lugar a dudas esta hipótesis requeriría de una verificación textual para que pueda ser aceptada en firme, pero es la vinculación más consistente que he sido capaz de encontrar.

Llegados a este punto no es difícil entender que la stasis aristotélica, la anaciclosis polibiana o la revolutio latina que pudiera acabar suplantando a la mutatio rerum inciden todas en la transformación de la unidad política, pero dentro de un campo de posibilidades cerrado. No hay lugar para la novedad en ninguna de estas formulaciones, y en el caso de los vocablos latinos, además, la concepción del tiempo histórico-cíclico propia de toda la Antigüedad clásica queda especialmente subrayada (Arendt, 2009: 26), por lo que el propio vocabulario latino hace que el horizonte de expectativa que va vinculado a revolutio sea, de hecho, un espacio de experiencia, un camino que ya ha sido transitado y que será transitado una y otra vez, vinculando revolutio con un eterno retorno de lo igual, aunque lo que esté en juego sea la transformación política. En el concepto de revolución tradicional no hay posibilidad para pensar la novedad o un futuro alternativo a la tradición, sino solo un continuo cambio circular de las formas políticas preexistentes.

De esta manera tenemos que un vocablo del mundo latino preñado de la tradición política clásica (con su noción de la temporalidad cíclica y cerrada) pasará a una lengua germánica erigiéndose como principal noción denotadora del conflicto político, y como significado más general de circularidad, recurrencia y restauración?

Pero será en los inicios de la edad moderna cuando el vocablo revolución comience a cobrar preeminencia en todas las lenguas que lo hayan tomado, incluido el inglés. En un principio vinculado a los desarrollos de la astronomía que llevaron a una recuperación del término revolución como movimiento cíclico y de retorno perpetuo aplicado al movimiento de las órbitas planetarias, llegando a aparecer en el título de la famosa obra de Copérnico De revolutionibus orbium caelestium (1543). La moda del uso del término revolución

9 Revolution (n.d.). Disponible en: https://www.merriam-webster.com/dictionary/ revolution. 
en la astronomía llevó a que muchos filósofos políticos del siglo xvir trasladasen por medio de metáforas científicas el término revolución al ámbito de la política. Un ejemplo dentro del ámbito anglosajón lo constituye Thomas Hobbes, quien dijo de la guerra civil inglesa al final de Behemonth (1668): «He visto en esta revolución un movimiento circular del poder soberano desde el difunto rey a su hijo a través de dos usurpadores» (Hobbes, 1668: 268; Koselleck, 1993: 71).

La cita de Hobbes es interesante porque pone de manifiesto que el concepto se está usando ya para hablar de una guerra civil, conservando y afianzando su sentido cíclico y de recurrencia que tenía en el mundo clásico y que se popularizó en la astronomía de la era moderna ${ }^{10}$. Para finales del siglo XVII el concepto va a estar lo suficientemente asentado como para nombrar el gran acontecimiento de la Revolución gloriosa de 1688. Sin embargo hay un significado de las formulaciones antiguas del concepto de revolución que quedó especialmente destacado durante la Revolución gloriosa, y que esta experiencia a su vez resaltaría. Y es la revolución como ejercicio supremo del derecho de resistencia frente a los poderes injustos.

El derecho de resistencia tiene una larga historia de simbiosis con la noción de revolución (González, 2010: 71-72). A grandes rasgos podemos decir que en Occidente existen dos genealogías del derecho de resistencia. Por una parte, la tradición clásica, que se inspira sobre todo en los escritos del bando senatorial de la segunda guerra civil romana, en especial en las reflexiones de Ciceron, así como en la Farsalia de Lucano, que se refiere a este mismo hecho histórico ${ }^{11}$. El humanismo italiano recuperaría esta tradición contraponiendo la virtud (vita

10 El estudioso de Hobbes Miguel León me ha sugerido a este respecto que la noción circular motion en Behemoth es una extrapolación metodológica de su trabajo en las ciencias naturales, donde estudia el movimiento circular no solo en relación con la astronomía, sino como problema mecánico relevante, siendo Galileo, más que Copérnico, su referente principal. Desarrollando esta idea, Miguel León sugiere que Hobbes desea precisar el sentido circular en que usa el término revolution para bloquear cualquier posible intento de darle a la palabra un sentido basado en su parentesco con revolt, que sería la precondición para tratar de hacer un balance positivo de los efectos de la guerra civil. Frente a ese riesgo, Hobbes reacciona explicitando la otra fuente de la que bebe el término, la mecánica, para así subrayar la idea de que todo el sufrimiento provocado por la guerra civil fue en balde, ya que en última instancia la única justicia que se podía restaurar era la que de hecho ya existía bajo el reinado de Carlos I. Este recurso de Hobbes es coherente con su permanente esfuerzo de trasposición metodológica de planteamientos procedentes de la geometría y la física al campo de la filosofía civil.

11 Tomo esta idea de Valerio Rocco y su asignatura Ciudadanía antigua y moderna. 
activa +vivere civile) del ciudadano a la tiranía de los príncipes. Idea que en Inglaterra popularizarían los humanistas ingleses de la corte de Enrique VIII (Pocock, 2008) y William Shakespeare en la corte de la reina Isabel I a través de su drama histórico Julio César.

Por otra parte, la tradición cristiana ha realizado una aportación fundamental a la teoría del derecho de resistencia. Tan es así que Hannah Arendt llega a considerar que «todas las revoluciones modernas son cristianas en su origen» (Arendt, 2009: 32), ya que reposarían sobre el principio de contestación a la autoridad en nombre de un mundo nuevo, idea cristiana que la modernidad liberaría en toda su potencialidad (ibid.: 32-34).

Esta idea, aunque sugerente, es muy matizable, pues supone ignorar la influencia del resto de genealogías en el concepto, así como la enorme influencia de la teología política paulina, que ha servido como fundamento para la obediencia a la autoridad por parte de las diferentes corrientes cristianas. Yo diría que en realidad la gran contribución del cristianismo a la popularización de la idea de revolución fue que hizo fácilmente comprensible en el proceso de secularización la idea de un futuro utópico mediante la sustitución de la idea del milenio por la de la sociedad emancipada. Esto explicaría cómo muchos grupos iletrados que no habían tenido contacto con las ideas de la Ilustración pudieron, sin embargo, captar todo su potencial revolucionario a través de su acervo cultural cristiano previo.

Lo que sí resulta claro es que el derecho de resistencia debe buena parte de su historia al cristianismo. Apoyados en los relatos del martirio de los santos en defensa de su fe ante las autoridades romanas, y en especial ante los emperadores, tanto en San Agustín como en Orígenes, se desarrolló la idea de resistencia ante la autoridad de este mundo en pos del mundo venidero (González, 2010: 78-81), y esta idea sí que será secularizada posteriormente por el marxismo, tal y como propone Arendt. La escolástica realizará un gran esfuerzo en delimitar el sentido sobre el derecho y la autoridad justa, frente a aquella que agrede los fines de la comunidad, a lo que se unirán las reflexiones de dos filósofos medievales tardíos, Marsilio de Padua con su Defensor Pacis (1324) y Guillermo de Ockham con sus lecciones en la Universidad de París, quienes serán los primeros teóricos en proponer que cuando un gobernante atenta contra las leyes de la ciudad, o bien no trabaja por el bien común, el pueblo tiene el derecho de deponerle o asesinarle (ibid.: 88-89).

De esta idea fundamental partirán los monarcómacos, que en el mundo latino tendrán un profundo desarrollo a partir de los escritos de la Escuela de Salamanca y de los jesuitas, teniendo a Juan de Mariana como ejemplo de ambas tradiciones. En el mundo protestante surgirán alrededor de ciertas líneas radicales del calvinismo teorizando y defendiendo el regicidio mediante una fusión de las ideas de Marsilio y Ockham con las de Calvino, como una forma de 
defender la libertad de creencia frente a las intromisiones de los monarcas. En Francia serán especialmente prolíficos como respuesta a la persecución de los hugonotes, con autores como Hotman y su Franco-Galia (1573) o Mornei y Languet con su famosa Vindiciae contra tyrannos (1579). En lengua inglesa serán fundamentales las contribuciones de los monarcómacos escoceses John Knox y John Buchanan, y en el siglo XviI los autores del puritanismo inglés y de Nueva Inglaterra fusionarán estas ideas monarcómacas con un derecho de resistencia y de expresión más general. Destacan en este campo los escritores John Milton con su Areopagítica (1644) y el leveller Richard Overton con su panfleto An arrow against all tyrants (1646) (ibid.: 99-100, 107-108), y como contribución de las colonias americanas al derecho de resistencia aparecerán los posicionamientos de los puritanos antinomistas Ann Hutchinson y Henry Vane en la controversia de las antinomias, junto con Roger Williams y Thomas Hooker en su enfrentamiento con los magistrados de Nueva Inglaterra, que introducirán la idea de libertad de conciencia en las colonias (Parrington, 1987: 51-62).

Todas estas contribuciones ${ }^{12}$ van a ser fundamentales para la justificación de la ejecución del rey Carlos I durante la guerra civil inglesa en términos de resistencia ante un tirano, así como en el levantamiento contra Jacobo II durante la Revolución gloriosa. John Locke tomará muchas de estas ideas en su Segundo tratado sobre el gobierno civil (2010), individualizando este derecho del pueblo como derecho natural de los individuos y asentando así una de las ideas clave que tomará el liberalismo político clásico desde la ideología Whig, y será fundamental a la hora de establecer el marco referencial de los Padres Fundadores durante la Revolución americana (Bailyn, 2012).

En el siglo Xviı el mundo anglosajón recuperará y popularizará la lectura de los autores grecorromanos como alternativa educativa a los textos sacros, por agotamiento político y cultural tras dos siglos de guerra civil religiosa (Reguera, 2012: 330-333). Tanto en la metrópolis como en las colonias las distintas generaciones que compondrán la Ilustración, y que en las trece colonias liderarán la Revolución americana, contarán en su imaginario con una concepción del tiempo histórico que combinará la idea de progreso junto con la propia de los autores clásicos y su sentido de circularidad, recurrencia y restauración vinculada a las nociones de revolutio; esta idea se verá reforzada por el propio uso del término en la ciencia, en especial desde la astronomía, a lo que hay que sumar las metáforas científico/políticas de los autores del siglo xvir, y toda la filosofía del derecho de resistencia que se ha expuesto vinculada también al término revolución.

12 Que son solo una muestra excesivamente simplificada de una tradición con muchos más nombres. 
Por lo tanto, a comienzos de la guerra de la Independencia americana, tendremos un concepto de revolución que expresará temporalidad circular y cerrada; que no solo no implica novedad histórica, sino que la niega; y que trae aparejada la idea del derecho de resistencia de la comunidad y los individuos ante todo poder tiránico e injusto, para así poder restaurar los derechos históricos y naturales. En todos los sentidos, el concepto tradicional de revolución durante sus últimos momentos será un concepto de espacio de experiencia, de justicia restauradora de derechos y constituciones históricas y naturales, y no un horizonte de expectativas de creación de un mundo nuevo. Pero cuando un mundo nuevo asoma en las páginas de la historia, los conceptos de espacio de experiencia o se adaptan o caen en el olvido.

\section{EXPLOSIÓN DE UN TÉRMINO PLURAL DURANTE LA GUERRA DE INDEPENDENCIA (1763-1786)}

La revisión de algunas de las fuentes de la Revolución americana ha revelado tres momentos distintivos en el uso y significación del concepto revolution.

Una primera fase iría desde el año 1763 a 1786, con el inicio de las protestas coloniales por la reestructuración imperial de 1763 (implementada por el Acta de Proclamación del mismo ańo), con limitaciones expansivas para los colonos hacia el Oeste, así como con nuevas cargas impositivas que llevarían a un levantamiento de las colonias. A la que seguiría la guerra de la Independencia, que comenzó en 1775 con las batallas de Lexington y Concord, y que finalizará en 1783 con el Tratado de París. Tras la que habría una turbulenta época de experimentación política y conflicto social en los recién creados Estados Unidos conocida como la Época Crítica (1783-1787), situación que daría lugar a un intento de estabilizar la Confederación con una constitución federal en 1787 (Bosch, 2010: 1-56).

En esta época es cuando aparece con fuerza el concepto de revolución como un concepto político central; como vía de expresión de los agravios sufridos por los colonos a manos del rey y el Parlamento inglés. Aunque durante la Revolución americana no será un concepto político fundamental en sentido koselleckiano, pues para ello tendría que haber una disputa por su significado (esto cambiará cuando estalle la Revolución francesa). Lo que sí muestran las fuentes, sin embargo, es una enorme polisemia del término durante todo el proceso. Hay múltiples significados por el hecho de ser tanto una metáfora científica como un término político, así como por ser un concepto en tránsito desde el ámbito del espacio de experiencia hacia una significación mayor como horizonte de expectativa (Kosellek, 1993: 337). 
Hasta donde he podido comprobar, el primer Padre Fundador en utilizar el término fue George Washington, en un despacho militar para su superior el coronel Stanwix en Fort Loudon (1757), por un enfrentamiento con los indios cheroquis durante el conflicto con Francia en la guerra de los Siete Años (1756-1763). En el despacho, revolution se refiere a una acción inusual de los indios que acechan Fort Cumberland, y toda la serie de sucesos fuera de lugar que acontecen allí (Washington, 1889a: 453). Pero el primer uso conflictual del concepto en Washington se da en una carta a William Crawford el 25 de septiembre de 1773, comentando el Acta de Proclamación aprobada una década antes, y a cuyos efectos él vaticina lo siguiente: «Pienso que no se debe perder el tiempo en tener [a los oficiales y soldados británicos] buscando [tierras que reclamar al oeste de los Apalaches], con el fin de que alguna nueva revolución pueda ocurrir en nuestro sistema político» (Washington, 1889b: 388).

La idea de una revolución por venir también está presente en John Adams, quien en una carta a James Warren en 1774 afirma: «Nuestros hijos podrían ser testigos de revoluciones, y ser partícipes y activos en moldearlas, en maneras que no podemos ni imaginarnos» (Adams, 1854: 337)

Ambos extractos muestran un uso del concepto de revolución como un fenómeno de futuro poco común en la época, en donde predominaba un sentido de revolución antiguo que denota circularidad y retorno (Koselleck, 1993: 70-71).

Los dos usos poco comunes que acabo de mostrar son el resultado de las tensiones imperantes entre, por una parte, el Parlamento y los gobernadores coloniales, y los colonos, por otra. Hay que recordar que cuando Washington escribe a Crawford los conflictos armados se encontraban prácticamente reducidos a las colonias de Nueva Inglaterra, y que cuando Adams escribe a Warren tan solo en esa región había un movimiento independentista notable, mientras que en el resto de las colonias reinaba un espíritu de reconciliación, tal y como se demostró en el Primer Congreso Continental y en las primeras sesiones del Segundo. Del comentario de Adams resulta interesante el matiz de novedad histórica que introduce, reflejando que la agitación política ya empieza a introducir horizontes de expectativa en un concepto que por lo demás sigue formando parte de los espacios de experiencia.

Según el conflicto vaya escalando, el horizonte de expectativa irá creciendo para John Adams, hasta convertir la revolución en un evento sin parangón para la historia de las naciones: «Los hechos más insignificantes, los eventos más triviales conectados con la gran causa americana devendrán importantes en esta situación crítica, cuando una revolución parece estar en los designios de la providencia, esta [la revolución] se vuelve tan importante como ningún hecho acontecido para la humanidad» (Adams, 1854: 361); 
«Nos encontramos en el mismo meollo de una revolución, la más completa, inesperada y notable en la historia de las naciones» (Adams, 1854: 394)

La primera carta (1775) está dirigida a Joshiah Quincy, y la segunda (1776), a William Cushing, y en ambas pueden apreciarse usos ya modernos del término revolución. Sobre todo por las referencias a lo inesperado, a la totalidad, lo nunca acontecido, todos estos son atributos que no estaban hasta el momento vinculados al concepto de revolución, con su referencia a lo recurrente, a la restauración. Lo que indica que el movimiento de independencia llevaba en su seno un poso de radicalidad que solo unos pocos de sus protagonistas fueron capaces de percibir.

Y aunque premonitorio, este uso del concepto revolución en términos que se acercan a su variante moderna va a resultar aislado. En el resto de Padres Fundadores el término revolution aparecerá en la inmensa mayoría de los casos referido como sinónimo de conflicto de la guerra de Independencia, experimentando una inflación sostenida en el uso del término a partir de 1776 con la Declaración de Independencia, por el hecho de la aceptación y toma de conciencia de la ruptura con la metrópolis.

Usos tales como «la presente revolución» (Hamilton, 1904a: 200; Adams, 1852: 107; Jefferson, 1900: 735) o «trece revoluciones del gobierno civil contra una nación muy poderosa» (Adams, 1852: 25) serán muy comunes, vinculando el término revolución a las nociones de guerra e independencia, lo que llevará a que una vez conseguida la independencia se popularice el término revolutionary war (Hyneman y Lutz, 1983a: 1112, 1208; Jefferson, 1900: 75, 123, 148; Adams, 1853: 616, 630; Hamilton, 1904e: 409) para lo que en la actualidad denominamos guerra de la Independencia americana. Hamilton lo expresa de manera clara años después en un panfleto firmado como Camillus (núm. XVIII [1795]) en donde habla de «una guerra revolucionaria, una guerra de la libertad contra la usurpación» (Hamilton, 1904e: 409), ofreciendo una definición escueta y precisa de lo que por aquellos tiempos se entendía por guerra revolucionaria, y en consecuencia por revolución en su uso más extendido.

Esta va a ser una época, por lo tanto, en la que convivan usos tradicionales del concepto de revolución con otros minoritarios aunque cada vez más significativos del uso moderno de revolución, como transformación y cambio. En 1774 el reverendo congregacionalista Gad Hitchcock asimilaba «revoluciones en el estado» con "disturbios y tumultos», y en el mismo escrito se refería a la revolución como "la sucesión de una ilustre casa» (refiriéndose a la corona en 1688), por lo que encontramos que el concepto antiguo de revolución aún se usa en su doble vertiente de rebelión y restauración. En la temprana fecha de 1762 el también reverendo congregacionalista Abraham Williams habló en uno de sus sermones de «todas las revoluciones del 
gobierno» (Hyneman y Lutz, 1983a: 13), siendo esta una expresión habitual en la bibliografía posterior. La expresión, muy común en la época, puede ser interpretada como sucesión de las formas de gobierno siguiendo el esquema polibiano, siendo el uso más probable en este caso.

Por otra parte, Hamilton utiliza en esta época expresiones más amplias del concepto revolution como «revolución en nuestras leyes» (Hamilton, 1904a: 115), entendida como un cambio de paradigma legal, o «revolución de los precios en general» (Hamilton, 1904c: 407), como una convulsión de los precios de la mayoría de los productos, aplicando el concepto al derecho y la economía.

Asimismo, Jefferson escribe a Madison en febrero de 1776: «Si los europeos vieran que todos los Estados se conducen por lo que la Asamblea de Virginia ha realizado, se produciría una revolución total en su opinión sobre nosotros y respecto a nosotros» (Jefferson, 1900: 158)

En este sentido, un cambio de parecer radical se entiende como revolución en la opinión, y se aplica también al ámbito de la opinión pública.

Por lo tanto, de 1763 a 1786 tenemos una popularización del término revolución auspiciado por la guerra de Independencia y las aspiraciones de cambio que esta trajo consigo. Sin embargo, este cambio, que se entiende como una ruptura espacial con la metrópolis, no es aún entendido como una ruptura temporal con el pasado y la tradición.

De hecho, la propia Declaración de Independencia, con su retórica de derechos inalienables, con su exposición de agravios y usurpaciones que justifican la separación, así como con el establecimiento de nuevos estados como solución al problema, resulta indicativa de la concepción política y del tiempo histórico que hay detrás de la ruptura (Jefferson, 2014: 20-25). La Declaración habla de formas de gobierno, lo que la inscribe aún en una concepción clásica de la política. En este sentido, la institución de un nuevo gobierno se justifica en "principios evidentes por sí mismos» (ibid.: 20), y por lo tanto como parte de una visión fundada en el espacio de experiencia y en una tradición que ha sido truncada y debe ser restituida, pero no en un horizonte de expectativas de una novedad radical. Es la restitución de una virtud que ha cesado por la corrupción de un rey que ha cometido el delito de usurpación y ha ejercido la tiranía, y por lo tanto, el ejercicio de un derecho de resistencia a un poder injusto que lleva a la separación como única solución, y no por el deseo de fundar un mundo nuevo sobre un sistema político nunca probado.

Sin embargo, la ruptura histórica que supone la primera experiencia descolonizadora de la historia es mucho más profunda de lo que muchos Padres Fundadores están dispuestos a admitir al inicio, y el sentimiento de novedad histórica que Adams entreveía en su intercambio epistolar va a irrumpir con tal fuerza en los debates sobre la nueva Constitución federal, que va a dejar obsoleto el concepto antiguo de revolución. 


\section{DEBATES SOBRE LA CONSTITUCIÓN FEDERAL Y POPULARIZACIÓN DEL CONCEPTO DE EXPERIMENTO (1787-1789)}

Es en este contexto en el que se convoca para la primavera de 1787 una nueva Convención Continental con el fin de reformar los Artículos de la Confederación aprobados una década atrás por el Segundo Congreso Continental para regir (en un sentido muy amplio) a los trece estados recién independizados y en proceso de creación de sus propias constituciones. El aparataje legal de los Artículos de la Confederación se reveló insuficiente para conducir las necesidades de la alianza, sobre todo tras la Rebelión de Shay acaecida en Nueva Inglaterra a finales de 1786 e inicios de 1787. En esta rebelión un grupo de veteranos de la Revolución americana se levantó en armas junto con muchos agricultores empobrecidos por la depreciación del dinero y los bonos de deuda con los que se les había pagado como compensación por sus servicios en la guerra. La rebelión fue aplastada, pero estuvo cerca de tomar Boston (Bosch, 2010: 49-50), y coincidió con un fuerte movimiento leveller en los estados del Sur, prefigurando una situación revolucionaria radical dentro de la Revolución americana. La élite colonial, los nuevos amos de la recién creada Confederación, aterrados y sin suficientes instrumentos de coacción, se decidieron a reformar las leyes que les unían para poder ofrecer una respuesta coordinada a futuras rebeliones. Y de este modo, si la Declaración de Independencia se redactó desde un espíritu emancipador y rupturista con el statu quo, la futura Constitución se redactaría desde un espíritu de orden y conservacionismo del nuevo orden político ${ }^{13}$.

La cuestión estaba entonces en la naturaleza de la reforma que se debía aplicar sobre los Artículos de la Confederación (siendo este un elemento de consenso entre casi todos los Padres Fundadores como una vía de defensa de sus privilegios). Pero pronto se formarían dos bandos por la implementación de la reforma: por una parte, estarían aquellos Padres Fundadores que querían transformar la arquitectura constitucional para generar un Gobierno central fuerte, con un ejército común, un banco central que pudiera emitir deuda pública y un Ejecutivo con herramientas de gestión política. Este grupo se autodenominaría los "federalistas». Opuestos a ellos, los defensores de las legislaturas estatales acabaron siendo conocidos como «antifederalistas», y estas dos fuerzas protagonizaron numerosos debates, de los más apasionados y profundos de la teoría política norteamericana.

13 Tomo esta idea de Carmen de La Guardia y su asignatura La Corrupción de la virtud: de las repúblicas a los imperios. 
El resultado fue la aprobación de la Constitución federal el 17 de septiembre de 1787 en la Convención Constitucional, y su ratificación por los estados (algunos con mucha resistencia) desde el 7 de diciembre de 1787, fecha en que Delaware se convierte en primer estado ratificador, hasta el 10 de enero de 1791, en que Vermont se convierte en el último estado en adoptarla. Pero en el terreno de la cultura política y en el concepto de revolución también se operó una gran transformación. En esta época se dio lo que Gordon S. Wood ha denominado «el fin de la política de los clásicos» (Wood, 1998: 606619), que resultó en un desvanecimiento de la referencialidad y los valores neoclásicos tan populares a inicios de la revolución, y que conllevó a una perdida y transformación en los valores republicanos asentados en la lectura y la reivindicación de los autores de la Grecia y la Roma clásica (Reguera, 2012: 335-339; Schlesinger Jr., 1988: 29).

Más exactamente, se dio un repunte del uso de los ejemplos clásicos en 1787, tras el cual se buscó un nuevo paradigma de referencia político. Dicho repunte es visible en elementos identitarios como el hecho de que Hamilton, Madison y Jay aún firmasen sus papeles del Federalista como Publius, y que sus adversarios firmasen como Brutus, así como es visible también en un sentido profundo en las numerosas referencias al mundo clásico que persisten en los propios papeles del Federalista. Sin embargo los debates entre federalistas y antifederalistas van a ser el canto del cisne del neoclasicismo político. Con ellos se pasaría de la idea de que la Revolución americana era la restauración de la virtud cívica robada por la tiranía, entendiendo revolución como parte de un esquema polibiano de tránsito de formas de gobierno virtuosas a corruptas, y virtuosas de nuevo (Polibio, 1996), a entender la experiencia revolucionaria como «el establecimiento de nuestro nuevo gobierno [que] parece ser el último gran experimento ${ }^{14}$ para la promoción de la felicidad humana por medio de un razonable pacto en la sociedad civil» (Washington, 1988: 537), en palabras de George Washington a la ciudadana Catherin M. Graham, en una carta escrita en 1790 que con el tiempo ayudaría a extender la idea de América como experimento.

Esta manera de plantear el sentido de la Revolución americana, o incluso la historia de Estados Unidos en su conjunto, no solo se popularizó entre los Padres Fundadores, sino que ha sido una idea recurrente en muchos historiadores del siglo xx como Carl L. Becker y su obra The United States: an experiment in democracy (1920) o el ensayo de Arthur Schlesinger Jr. America: Experiment or Destiny (1977), incluido y divulgado en su colección de ensayos titulada The Cycles of American History (1987). Así lo atestigua Schlesinger Jr.:

14 Subrayado mío. 
Los Padres fundadores vieron la república americana, no como una consagración divina, sino como la prueba de una hipótesis frente a la historia. Pero la misma fe en el experimento implicaba el rechazo del dogma republicano clásico de que el tiempo originaba inevitablemente la decadencia. «Los hombres que hicieron la constitución" escribe Henry Adams "pretendían mediante ella dirimir una cuestión con la Antigüedad» [...] En palabras de John P. Diggins: «Mientras que la tesis de Maquiavelo supone que la virtud sólo puede reinar con el tiempo y que el tiempo también amenaza la virtud, la tesis federalista supone que el tiempo es básicamente redentor, no destructivo... El esquema maquiavélico presupone la futilidad del tiempo, el de Madison su fertilidad». De modo que el experimento era el modo de escapar del destino clásico republicano (Schlesinger Jr., 1988: 29).

Por lo tanto vemos que el concepto de experimento llegó para instaurar una nueva consciencia histórica implícita en las rupturas que el proceso revolucionario estaba implicando, pero que el concepto de revolución tradicional y la tradición clásica no podían reflejar. El tiempo como fenómeno político dejaba de ser una amenaza para convertirse en una oportunidad, y el futuro, con sus horizontes de expectativas, cobraba un nuevo significado. Ya no se trataba de volver a instaurar formas de gobierno virtuosas tras la revolución, sino de atajar los problemas del presente con soluciones del presente, y mirando hacia el futuro.

Después de dejar la presidencia el propio Jefferson pondría palabras a esta superación de referentes clásicos en una carta a Isaac Tiffany (1816) considerando la futilidad de los antiguos como referente para el gobierno, tal y como se puede apreciar en este comentario sobre los escritos políticos de Aristóteles:

Tan diferente era el tipo de sociedad entonces y para esas gentes de lo que existe ahora y para nosotros, que considero que poco aprendizaje puede obtenerse de sus escritos sobre el gobierno [...] El más absoluto experimento de un gobierno, democrático y representativo a la vez, nos ha sido reservado a nosotros. [...] La introducción de este nuevo principio de la democracia representativa ha dejado obsoleto prácticamente todo lo escrito con anterioridad acerca de las formas de gobierno (Jefferson, 1900: 51).

Una vez más, el concepto de experimento está presente para subrayar la ruptura con el pasado ${ }^{15}$, en esta ocasión referido a la mismísima tradición

$15 \mathrm{Y}$ en este caso además con la historia entendida como Historia Magistra Vitae, como una colección de ejemplos a emular y de los que se puede y debe aprender. 
aristotélica, que no solo fue el eje vertebrador de la principal tradición política de Occidente, sino que además era una pieza vital en los orígenes y desarrollo del concepto tradicional de revolución, como ya vimos. Si el esquema aristotélico ya no era válido, el polibiano, tampoco, salvo la noción de constitución mixta (la República romana), como superadora del esquema de la anaciclosis de las formas de gobierno simples. Sin duda esta idea (pasada previamente por Montesquieu y Locke) es el motivo que subyace a la idea de la democracia representativa como experimento americano. Un sistema nacido del presente, sin referencia al pasado, y que debe durar para siempre, evitando con su equilibrio y moderación la disolución de la comunidad política. Con este cambio la idea misma de utopía política comienza a posarse sobre el concepto de revolución en los últimos años de nuestro estudio.

Aún con todo, el concepto de experimento no era nuevo. Llevaba mucho tiempo utilizándose, sobre todo en el ámbito científico. De hecho, compartía espacio lingüístico en la física con el concepto de revolución aplicado a la astronomía. Jefferson los utilizará ambos tanto para sus escritos científicos como para los políticos, por lo que no es raro que los Padres Fundadores los acabasen asimilando.

Antes de los debates constitucionales de 1787 el concepto de experimento ya tenía usos políticos durante la revolución. El reverendo congregacionalista Phillis Payson en 1778 se refiere a la posibilidad de una religión estatal (debatida durante la revolución) como un "peligroso experimento en el gobierno", y recomienda aplicar las lecciones de la historia, la filosofía y la política mediante "observación y experimento" (Hyneman y Lutz, 1983a: 530), convirtiéndose esta última fórmula en una coletilla común del lenguaje político para hablar de lo que hoy llamaríamos reforma.

Pero no reforma como antítesis de revolución, pues de hecho en esta época revolución va a empezar a equipararse con reforma como cambio gradual en una forma política que puede transformarse hacia algo nuevo sin alterar el conjunto del orden social. Así lo entendió John Adams en un discurso ante los estudiantes del College of New Jersey en 1798 siendo presidente (Adams, 1854: 206).

Aunque el momento clave para el afianzamiento del concepto de experimento será durante los debates para la adopción de la Constitución federal.

En la Asamblea de Massachusetts se hablará de que va a acontecer una «revolución constitucional» en menos de dos años por las elecciones a representantes, lo que también será llamado «una revolución general en el gobierno» (Elliot, 1836a: 77-78, 167-168), y a la Constitución se la denominará «un gran experimento político» (ibid.: 154). En Nueva York revolución se asimilará a guerra civil (ibid.: 335), así como a la guerra de Independencia. La Constitución será denominada «nuevo experimento en política» $\mathrm{y}$ «nuevo 
sistema» (ibid.: 219), y Hamilton advertirá que sin la estabilidad que proveerá la constitución los americanos estarían condenados a «realizar experimentos sin fin» (ibid.: 302). En Pensilvania el representante James Wilson dirá que la idea de «una revolución en el gobierno» en el resto del mundo se considera algo violento y a evitar, pero que la experiencia americana demuestra lo contrario (ibid.: 433). Por lo tanto vemos que en los estados del Norte revolución y experimento se vinculan para esta época ya con transformaciones políticas, y que el concepto de experimento es el que imprime el sentido de novedad asimilado a la noción de constitución, que es lo que se considera que nunca se ha probado.

En los estados del Sur la relación con el concepto de experimento no va a resultar tan armoniosa, sobre todo porque se teme que la nueva Constitución pueda poner en peligro la soberanía de los estados, y aquí hay cabida para razonamientos tanto por parte de los proponentes de la soberanía popular como entre los defensores de la esclavitud. La mayor controversia se dará en Virginia entre Patrick Henry, receloso del experimento, y James Madison, ardiente defensor del mismo. Henry dirá: «A menos de que exista un gran y terrible peligro, no se deberá probar ni cambios ni experimentos» (Elliot, 1836b: 151). En esta misma tónica dirá que "todo hombre en este comité debería estar alarmado sobre el hecho de realizar experimentos inusuales en el gobierno» (ibid.: 172), a lo que Madison responderá que no ve razones para estar alarmado al hacer experimentos basados en los mejores principios (ibid.: 398) y desvinculará los experimentos en la forma republicana de gobierno de la anarquía; lo que supondrá defender la necesidad de los experimentos en términos muy similares a Hamilton (ibid.: 394, 399-400). Y esto no debe ser motivo de sorpresa, pues ambos moldearon el sentido del concepto de experimento en los papeles del Federalista.

En el Federalista núm. 39 Madison se pregunta si la forma de gobierno para América debe ser estrictamente republicana. Y contesta que sí, pues es la única que el pueblo americano puede aceptar, y esto es así por su experimento político que se basa en la capacidad del hombre para el autogobierno (Hamilton, Jay y Madison, 2001: 194). En el Federalista núm. 40 Madison describe el experimento como la corrección de los errores de un sistema (ibid.: 204) y en el Federalista núm. 85 Hamilton ensaya la idea, que luego expondrá en la asamblea de Nueva York, de que sin la Constitución «se expone a la Unión al peligro de sucesivos experimentos, en la búsqueda quimérica de un plan perfecto" (ibid.: 454-455).

Lo que todos estos usos del concepto de experimento demuestran es que en los años del debate constitucional americano dicha noción se está utilizando para referirse al campo de significados que unos ańos más tarde, y hasta nuestra época, adquirió el término de revolución. Es decir, como un 
espacio de experiencia política que abre un nuevo horizonte de expectativa. Como una transformación política que a través de lo nunca probado ayuda a alumbrar un mundo nuevo. El concepto de experimento es la formulación de la noción de revolución que podía producir una clase burguesa (o plantadora en muchos casos) e ilustrada como la de los Padres Fundadores, y una Ilustración además basada en el empirismo. Una transformación realizada mediante la experimentación a partir de principios de gobierno que buscan la estabilidad mediante el equilibrio institucional. Un concepto de transformación limitada propio de una élite que quiere conservar su poder recién adquirido.

Sin embargo es un concepto central para el alumbramiento de la noción de revolución como transformación radical, pues ayuda a romper con la idea de la revolución como retorno y restauración, y encarrila el concepto hacia una concepción del tiempo histórico cifrado en términos de progreso y novedad. Sobre todo porque la noción de experimento introduce la distinción entre una fase de conflicto violento de ruptura, seguida por otra fase posterior al conflicto donde se sigue realizando una transformación social con base en la modelación de nuevas instituciones según principios políticos. Esto es algo novedoso, pues el concepto tradicional de revolución como rebelión hacía referencia al hecho insurreccional, pero una vez restaurado el orden la revolución acababa y se volvía a alguna de las viejas formas de gobierno. El concepto de experimento, por el contrario, abre la puerta a poder pensar en una revolución permanente que trasciende el período de lucha.

Puede que ningún documento haya influido tanto en la popularización y extensión de la noción de experimento como la más famosa locución del primer discurso inaugural de George Washington (1789), que vinculó la labor del experimento a una suerte de misión nacional: «La preservación del fuego sagrado de la libertad y el destino del modelo republicano de gobierno son justamente considerados, quizá, profundamente, finalmente, como ligados al experimento confiado al pueblo americano» (Washington, 1988: 426) (Schlesinger Jr., 1988: 29)

El experimento ya no se trata solo de una fase más de la revolución como parte del desarrollo institucional y la necesidad de probar novedosas formas de gobierno, sino que forma parte de un plan providencial vinculado a un espíritu cívico, el deber de preservación del «fuego sagrado de la libertad y el destino del modelo republicano de gobierno» "confiado al pueblo americano». El deísmo que Washington comparte con muchos otros Padres Fundadores le lleva a considerar el experimento como una misión providencial, redentora, expansiva y universal, tal y como los girondinos y jacobinos considerarán tres años después la revolución cuando comiencen a extender su credo a través de guerras defensivas a lo largo y ancho de Europa. 
Se inaugura por tanto una nueva forma de comprender el experimento, que en Francia se asimilará al concepto de revolución. La idea de un destino universal de la humanidad vinculado a una experiencia transformadora que debe replicarse y extenderse por todo el mundo, así como convertirse en el signo de la época. Podemos encontrar esta idea claramente en una carta a John Adams de 1796, en que Jefferson le confiesa que «esta, espero que sea la era de los experimentos en el gobierno" (Jefferson, 1900: 386), y cinco años más tarde en su discurso de investidura como presidente dirá a la ciudadanía que los principios de gobierno (americanos) guían «nuestros pasos a través de una era de revolución y reforma» (ibid.: 327). Lo que en un principio iba a ser la era de los experimentos en el gobierno acaba convirtiéndose en la era de la revolución y la reforma. Este desplazamiento conceptual es importante y se produce en la Revolución francesa, de su radicalismo y de cómo a partir de esta experiencia se acabaron por reformular las transformaciones en el concepto de revolución que se había iniciado en la Revolución americana.

\section{TERCERA FASE DEL CONCEPTO REVOLUTION EN LA REVOLUCIÓN AMERICANA: RADICALIZACIÓN DEL CONCEPTO POR LA REVOLUCIÓN FRANCESA (1789-1824)}

La última gran transformación del concepto revolution que se atisba en las fuentes se encuentra vinculada al enorme y contradictorio impacto que tuvo la Revolución francesa en la joven república estadounidense. Enorme y contradictorio porque si bien muchos celebraron que sus antiguos aliados siguiesen el mismo camino de emancipación que ellos habían transitado, los federalistas temían que la Revolución francesa pudiera radicalizar a sus propios ciudadanos y poner en peligro el restablecimiento de las relaciones comerciales con Inglaterra.

Aquellos que podían tener esperanzas en que la guerra faccionalista terminase con la aprobación de la Constitución en todas las legislaturas estatales vieron su sueño truncado por un reavivamiento de la lucha faccional entre aquellos que apoyaban a Francia o a Inglaterra por el conflicto europeo, lo que no suponía solamente elegir entre una política exterior internacionalista (la seguida por Jefferson y los republicanos) o aislacionista (la elegida por Washington, Adams, Hamilton y los federalistas), sino que además suponía posicionarse sobre el significado y la radicalidad del proyecto revolucionario y del experimento republicano de Estados Unidos.

De hecho, su experiencia revolucionaria les sirvió a los americanos para prever la Revolución francesa antes de que esta sucediera. En su correspondencia con el marqués de Lafayette, Washington utiliza en varias ocasiones el 
término revolución para referirse a la agitación en la Francia prerrevolucionaria. El 19 de junio de 1788 Washington le realiza a Lafayette una advertencia premonitoria a solo un ańo de la toma de la Bastilla: en su opinión, la actitud del rey Louis XVI ante el Parlamento (los Estados Generales) va a encender la llama del descontento entre los franceses, por lo que aconseja a Lafayette que le sugiera a Louis XVI que realice «una revolución gradual y tácita en favor de sus súbditos, mediante la abolición de los cuadernos de quejas y definiendo [diferenciado] mejor los poderes del gobierno» (Washington, 1988: 401).

Con el comienzo de la revolución en Francia, los Padres Fundadores de tendencia más conservadora no pudieron reprimir sus suspicacias ante el evento, incluso antes de su radicalización en tiempos del Terror. Así puede apreciarse en una carta de John Adams a Richard Price en 1790:

La revolución en Francia no podría dejarme indiferente; pero la experiencia me ha enseñado con amargura a regocijarme con un estremecimiento: Sé que los enciclopedistas y economistas: Diderot y D' Alembert, Voltaire y Rousseau, han contribuido a este gran evento más que Sidney, Locke o [Benjamin] Hoadley, posiblemente más que la Revolución americana; y te advierto, que no sé qué podría hacer una república de treinta millones de ateos. La constitución [americana] no es otra cosa que un experimento, y será alterada [por los acontecimientos]» (Adams, 1854: 563-564).

Esta no es la única carta de preocupación de Adams. Ese mismo año escribe a Alexander Jardiner para advertirle de que aquellos que dirigen las revoluciones son espíritus fieros poco dados a la reflexividad y la calma, más interesados en inflamar a las masas que en buscar la verdad, y que este peligro amenaza a Francia. Pues el deseo de cambio en Francia es poderoso y eso no le agrada. Por otra parte él se siente muy satisfecho con sus propios principios, los de la Revolución americana, que juzga eternos y cree que acabarán prevaleciendo en el mundo, pues representan el equilibrio y la mesura (Adams, 1854: 567-568).

Por supuesto Adams habla más desde sus miedos personales que desde su brillante capacidad analítica, pues el impacto de la Revolución americana en la Revolución francesa fue mucho más fluido y profundo de lo que está dispuesto a admitir, de hecho, si no fuera así, su miedo al contagio de la radicalidad desde Francia a América sería infundado. De la misma manera, la Revolución americana tuvo un impactó en el mundo atlántico como una onda expansiva, sacudiendo múltiples países y generando insurrecciones que tomaron el caso americano como modelo. Francia fue otra pieza más del dominó en esa onda expansiva, pero una pieza singular que por sus contradicciones internas e importancia geopolítica replicaría una 
onda expansiva aún mayor que no solo haría tambalearse a Europa sino a todo un régimen histórico, de ahí su radicalidad y radicalización. Por otra parte, incluso en el uso del término revolución en Francia influyeron las relaciones transatlánticas.

Arendt especula que el primer uso del término revolución en Francia corresponde al duque de La Rochefoucauld-Liancourt advirtiendo al rey de los ánimos del pueblo de París a dos días de la toma de la Bastilla. Louis XVI exclamó: «iEs una revuelta!», y el duque matizó: «No, señoría, es una revolución» (Arendt, 2009: 62-63). Sin embargo, la anécdota es demasiado redonda y posiblemente sea apócrifa. Dorinda Outram, por otra parte, identifica al conde de Mirabeau durante los Estados Generales como el primero en utilizarlo en Francia. Después de esto, el término se habría utilizado de manera caótica e indiscriminada durante el Terror, lo que habría llevado a Condorcet a escribir y pronunciar en la Asamblea Nacional su famoso discurso Sobre la revolución: sobre el significado de la palabra "revolucionario» (1793), tan solo un día antes de ser purgado de la Asamblea junto con el resto de girondinos (Outram, 1987: 140-141, 144).

El caso de Condorcet es interesante, pues junto con el marqués de Lafayette es uno de los principales ilustrados franceses que tuvieron una relación de amistad directa con los Padres Fundadores, manteniendo un intercambio de ideas. La influencia de Thomas Jefferson para ambos es decisiva en el desarrollo de la Revolución francesa, no en vano, el primer borrador de la Declaración de los Derechos del Hombre y el Ciudadano lo escribieron los tres, Lafayette, Condorcet y Thomas Jefferson, en casa de este último (embajador estadounidense en Francia en ese momento) tomando como inspiración la Declaración de Derechos del Estado de Virginia escrita por George Manson (Jefferson, 1900: 91; Jefferson, 2014: 96-97; Schofield, 2010: 307). Condorcet y Jefferson se hicieron amigos por intercesión del embajador saliente, Benjamin Franklin, cuando Jefferson llegó para sustituirle, quedando los tres unidos por su labor de ilustrados en el progreso político, el cultivo de la ciencia y su visión fisiocrática compartida. Y de esta amistad Jefferson tomará la fundamentación lógico-teórica para su fisiocracia, y Condorcet, muchas de las ideas políticas de Jefferson (Schofield, 2010). No es descabellado pensar, de hecho, que compartiendo ambos lenguaje científico en que usaban el concepto de revolución, y el hecho de que Jefferson ya utilizase profusamente el término revolución para la política siendo embajador en Francia, Condorcet obtuviera una sensibilidad especial con el término que le llevase a escribir su escrito Sobre la revolución en las postrimerías de su caída en desgracia.

En su escrito, Condorcet reclama que el término revolución está hecho para la Revolución francesa, una revolución formada para la libertad, que es el 
verdadero significado de revolución como lucha contra la tiranía ${ }^{16}$. Y Condorcet comienza entonces a considerar las formas en que el adjetivo revolucionario puede utilizarse para los supuestos en que se dé adhesión, avance o triunfo de la libertad (Condorcet, 2012: 190). El hecho de que Condorcet deba afanarse en definir el término revolución refleja que el término se ha convertido en un concepto político fundamental: un concepto político y polémico central por cuya definición pugnan los actores. Asimismo, nos pone sobre la pista de que el término ya es plenamente moderno.

La realización del tránsito a un concepto moderno de revolución se caracteriza por que este pasa a referirse a un horizonte de expectativa, a una perspectiva de transformación social con base en un conflicto que tiene en su base unos principios políticos sobre los que construir una sociedad nueva a partir de ellos.

Pero la transición no fue sencilla en Estados Unidos, pues significaba vincular el término revolución a un horizonte de radicalidad que muchos temían, y por eso hubo una batalla por definir el concepto de revolución en términos no radicales, incluso aunque eso supusiera volver al significado antiguo. En Estados Unidos el concepto de revolución pasaba a convertirse también en un concepto político fundamental y polémico. Esto se puede apreciar en un texto publicado por Hamilton bajo el pseudónimo de Americanus en 1794:

Si se les deja a ellas mismas [las potencias europeas] todas ellas salvo una [Francia], con naturalidad verán en nosotros a un pueblo que restauró mediante una revolución en el gobierno, un refugio contra la usurpación de los derechos y privilegios anteriormente disfrutados, y no como un pueblo que por elección ha escogido un cambio radical y completo en el establecimiento de su gobierno, en la búsqueda de nuevos privilegios y derechos, llevados a un extremo, tal vez irreconciliable con cualquier forma de gobierno compartida. Ellos verán en nosotros a un pueblo que muestra respeto por la propiedad y la seguridad personal, que, en medio de una revolución, se abstuvo con ejemplar moderación por cualquier recurso violento o sanguinario, instituyendo un gobierno adecuado para la protección de las personas y la propiedad (Hamilton, 1904e: 94-95).

Tal y como se puede comprobar, y a pesar de los esfuerzos de Hamilton, el término revolución no se deja embridar por su antiguo significado como «restauración», y enseguida aparecen las referencias al cambio radical, a la violencia y a las formas de gobierno nunca probadas. Esto demuestra que los cambios conceptuales devienen de una combinación de tres factores:

16 Claramente Hannah Arendt toma su noción normativa de revolución de estas palabras de Condorcet. 
- Las tradiciones discursivas en que transitan y se emplean los conceptos.

- Los eventos históricos que dan soporte material y plausibilidad explicativa a los conceptos condicionando su significado durante momentos de ruptura que quiebran las tradiciones.

- Los actores y su capacidad de pugnar por el significado de los conceptos en el momento que los eventos históricos trastocan las relaciones de poder.

La Revolución americana fue un primer golpe de obsolescencia sobre el concepto antiguo de revolución, lo que provocó la aparición del concepto de experimento para poder satisfacer la necesidad de hablar sobre la novedad histórica. La radicalidad de la Revolución francesa permeó en el concepto obsoleto y le dio una nueva significación a la que ya no se podía dejar de aludir, y por lo tanto el concepto se volvió imprescindible, incómodo para los defensores del status quo, a la par que fundamental para los que aspiran a su transformación, que a su vez les llevó a abandonar el uso político del concepto de experimento en aras de un nuevo término de mayor alcance explicativo.

Esto resultó un problema para los federalistas, pues los Estados Unidos se fundaban en una revolución, y su significado radical arrojaba una sombra sobre su propio proyecto, pues el hecho de que Francia y Estados Unidos fueran repúblicas con un origen revolucionario hacía que muchos estadounidenses simpatizasen con la Revolución francesa. Por lo que los federalistas intentaron desacreditar el término revolución, contraponiéndolo al de experimento.

Prueba de esto son las lecciones del profesor de Derecho del Columbia College James Kent, quien en 1794 considera que se están llevando a cabo grandes revoluciones en Europa en los terrenos del gobierno, la política y la moral; lo que supondrá nuevas formas de pensar y sobre el destino de la sociedad. La demolición de los fundamentos del antiguo orden servirá para romper las cadenas de la opresión en Europa, pero esa nueva pasión por la novedad, para Kent, no hará ningún bien en América, pues podría malograr todo lo que se ha logrado. Por tanto, Kent propone continuar por la senda de libre investigación y experimento de buena fe que comenzaron los patriotas revolucionarios (Hyneman y Lutz, 1983b: 948-949).

El pastor baptista Jonathan Maxci, por su parte, advirtió a su congregación contra los «demagogos revolucionarios», maravillados con «revoluciones perpetuas» y que solo hablan de igualdad y quieren implantar democracias, es decir, asambleas de hombres reunidos que son tan tiránicas como las monarquías despóticas. «Modernos zelotes de la reforma revolucionaria» que proponen que la ciencia del gobierno es la más sencilla. Pero Maxci se opone a esta idea, pues para él la ciencia del gobierno se basa en principios, y la única manera de deducirlos es mediante el experimento (ibid.: 1053-1054). 


\section{CONCLUSIONES}

Sin embargo todos estos intentos de contraponer la revolución al experimento (entendido ahora este como una transformación moderada y razonada) van a ser en balde. Pues por muy moderado y procesual que fuera el significado de experimento como transformación, este se usaba en el mismo terreno referencial en el que se estaba utilizando el término revolución. Por lo tanto, la contraposición no prosperó y lo que ocurrió fue que el término de experimento volvió a quedar otra vez relegado a las ciencias, mientras que el de revolución terminó de desplazarlo definitivamente y de constituirse como concepto de transformación y de horizonte de expectativas.

Prueba de ello fueron las elecciones presidenciales de 1800, en las que Jefferson derrotó a Adams, con lo cual los federalistas perdieron el poder gubernamental, ascendiendo los republicanos de Jefferson, simpatizantes de la Revolución francesa. A estas elecciones se las llamó la «Revolución de 1800", y no solo por sus detractores, también por los vencedores de las mismas. Así lo expresó Jefferson en 1819, unos años después de dejar su cargo, a Spencer Roane: «La revolución de 1800 fue una verdadera revolución en los principios de nuestro gobierno, como la revolución de 1776 lo había sido en su forma; no efectuada, de hecho, por medio de la fuerza, como la anterior, sino por medio del racional y pacífico instrumento de la reforma, del sufragio popular» (Jefferson, 1900: 741)

El concepto de revolución se encontraba, pues, no solo normalizado sino suficientemente aceptado como para poder designar una presidencia. A pesar del tono optimista de Jefferson, sus dos mandatos distaron mucho de ser una revolución, y de hecho terminará de instituir el programa federalista que decía combatir. Sin embargo también puso las bases para todos los movimientos democratizadores de la década siguiente. Y lo que la Revolución de 1800 muestra es que el concepto de revolución moderno se encuentra plenamente operativo. La crisálida ha terminado de romperse y de su interior ha surgido un concepto que apunta hacia el progreso, que se materializa como horizonte de expectativa, que vincula el ahora con el mañana, sin importar los fundamentos del ayer, y en muchas ocasiones, se constituye a pesar de estos.

El concepto antiguo de revolución era un espacio de experiencia, porque ofrecía un esquema de transformación cerrado sobre sí mismo y ajeno a la novedad histórica, porque el bien se encontraba en el pasado, en una edad de oro perdida que había que recuperar, y por eso se hacían las revoluciones. El concepto antiguo de revolución creía en las ucronías. Por el contrario, el concepto de revolución moderno es un horizonte de expectativa, porque afirma que nada bueno puede sacarse del presente y del pasado, y por eso mira hacia el futuro animado por la fe en el progreso, y por ello cree en las utopías. 
El tránsito del concepto antiguo de revolución al moderno se cifra en la transformación de la creencia social de que ya no existen las edades de oro perdidas, sino que las edades de oro están por llegar y se conquistan. La transición de un concepto a otro no solo nos habla de un cambio en el significado del lenguaje político, sino también en la concepción de la temporalidad: cómo la viven, la imaginan, y cómo viven y se comprenden a sí mismos a través de esta.

La Revolución americana puso sobre la mesa un horizonte político distinto al que la tradición política había postulado desde Aristóteles. Esta situación llevó a que el concepto de revolución tradicional quedase superado y apareciese el concepto de experimento como una forma de transición que diera cuenta del nuevo escenario. La Revolución francesa supuso la gran ruptura con el orden social precedente y por ello se significó con una gran radicalidad política de la que la Revolución americana carecía, y recuperó el concepto de revolución cargándolo con un sentido de transformación radical. Cuando los Padres Fundadores del Partido Federalista fueron conscientes del nuevo significado que el concepto de revolución estaba experimentando por causa de la Revolución francesa, intentaron contraponer revolución como cambio radical a experimento, entendido como transformación gradual. Pero el término había calado entre la población, y el concepto de revolución quedó fijado en el vocabulario político como el paradigma lingüístico de los horizontes de expectativa.

\section{Bibliografía}

Adams, J. (1852). The Works of John Adams. Vol. VII. Boston: Little, Brown and Company.

- (1853). The Works of John Adams. Vol. VIII. Boston: Little, Brown and Company. (1854). The Works of John Adams. Vol. IX. Boston: Little, Brown and Company.

Arendt, H. (2009). Sobre la revolución. Madrid: Alianza Editorial.

Aristóteles (2010). Política. Madrid: Alianza Editorial.

Bailyn, B. (2012). Los orígenes ideológicos de la Revolución norteamericana. Madrid: Tecnos.

Bosch, A. (2010). Historia de los Estados Unidos 1776-1945. Barcelona: Editorial Crítica.

Condorcet, N. (2012). Political writings. Cambridge: Cambridge University Press.

Elliot, J. (1836a). The debate in the state conventions on the adoption of the federal constitution. Vol. II. Washington: Jonathan Elliot Printer.

- (1836b). The debate in the state conventions on the adoption of the federal constitution. Vol. III. Washington: Jonathan Elliot Printer.

González, F. (2010). Teoría de la revolución: sistema e historia. Madrid: Plaza y Valdés editores, Consejo Superior de Investigaciones Científicas.

Hamilton, A. (1904a). The works of Alexander Hamilton in twelve volumes. Vol. I-XII. New York: Putman's and Sons.

Hamilton, A. Jay, J. y Madison, J. (2001). The Federalist. Indianapolis: Liberty Fund.

Hobbes, T. (1992). Behemoth. Madrid: Tecnos. 
Hyneman, C. y Lutz, D. (1983a). American political writings during the Founding Era 17601805. Vol. I. Indianapolis: Liberty Fund.

- (1983b). American political writings during the Founding Era 1760-1805. Vol. II. Indianapolis: Liberty Fund.

Jefferson, T. (1900). The jeffersonian cyclopedia: a comprehensive collection of the views of Thomas Jefferson edited by John P. Folley. New York: Funk y Wanalls.

- (2014). Escritos políticos: declaración de independencia, autobiografia, epistolario. Madrid: Tecnos.

Koselleck, R. (2009). Introducción al Diccionario histórico de conceptos político-sociales básicos en lengua alemana. Revista Anthropos, 223, 92-105.

(1993). Futuro Pasado: para una semántica de los tiempos históricos. Barcelona: Paidós.

Locke, J. (2010). Segundo tratado sobre el gobierno civil. Madrid: Tecnos.

Parrington, V. (1987). Main Currents in Americna Thought.Volume 1. The Colonial Mind 16201800. Norman: University of Oklahoma Press.

Outram, D. (1987). Words and institutions during the French Revolution: The case of «revolutionary» scientific and technical education. En P. Burke, P. y R. Porter (eds.). The social history of language (pp. 120-135). Cambridge: Cambridge University Press.

Pocock, J. (2008). El momento maquiavélico: el pensamiento politico florentino y la tradición republicana atlántica. Madrid: Tecnos.

Polibio (1996). Historias: libros V-XV. Madrid: Gredos.

Reguera, M. (2012). Patriotismo y romanidad en la Revolución americana: el patriotismo ilustrado y su tránsito al moderno nacionalismo. Encuentros en Catay, 26, 330-342.

Schlesinger Jr., A. (1988). La teoría de América jexperimento o destino? En Los ciclos de la historia americana (pp. 21-40). Madrid: Alianza Editorial.

Schofield, N. (2010). The intellectual contribution of Condorcet to the founding of the US Republic 1785-1800. Social Choice and Welfare, 25, 303-318. Disponible en: https:// doi.org/10.1007/s00355-005-0005-y.

Washington, G. (1889a). The writings of George Washington: collected and edited by Worthington Chauncey Ford. Vol. I, 1748-1757. New York: G.P. Putman's and Sons.

- (1889b). The writings of George Washington: collected and edited by Worthington Chauncey Ford. Vol. II, 1758-1775. New York: G.P. Putman's and Sons.

— (1988). George Washington, a collection. Indianapolis: Liberty Fund.

Williams, R. (2000). Palabras clave: un vocabulario de la cultura y la sociedad. Buenos Aires: Ediciones Nueva Visión.

Wood, G. (1998). The creation of the American republic 1776-1787. Chapel Hill: The University of North Carolina Press. 